\section{Rock avalanche run-up record}

SIR-During movement along its path, rock-avalanche debris can exhibit spectacular mobility in surmounting substantial topographic obstacles ${ }^{1}$, in running up opposing slopes ${ }^{2}$, and in the superelevation of its surface in valley bends in its path $^{2}$. In investigating the run-up at the Avalanche Lake rock avalanche located at $62^{\circ} 25^{\prime} \mathrm{N}, 127^{\circ} 15^{\prime} \mathrm{W}$ in the uninhabited Mackenzie Mountains of the Cordillera of western Canada, I have documented a run-up that is both highly anomalous and the highest ever recorded.

The avalanche was first reported by Gabrielse et al. $^{3}$. It is one of several highly mobile rock avalanches in the Mackenzie Mountains described by Eisbacher ${ }^{4}$ and is the most recent of multiple rock avalanches near Avalanche Lake. It involved the detachment of an estimated 5-6 $610^{8} \mathrm{~m}^{3}$ of Palaeozoic limestone along a remarkably planar bedding surface dipping at about $31^{\circ} \mathrm{S}$ towards the valley (see figure). The disintegrating rock mass descended into the valley where most of it was deposited, forming a dam that impounded Avalanche

Lake. Some of the debris, however, travelled over the valley floor and up the precipitous south side of the valley (the wall) to elevation $1,640 \mathrm{~m}$ above sea level. It then spread out on a feature called the shelf, running up a further $30-60 \mathrm{~m}$ at its southern margin. The deposits are called the shelf lobe.

It can be estimated from part $a$ of the figure that the height of the descent slope, $h_{1}$ - the elevation difference between the top of the headscarp and the bottom of the pre-landslide valley - is $1,220 \mathrm{~m}$ and that the maximum height of the run up, $h_{2}$, is $640 \mathrm{~m}$. Using the simple velocity head formula ${ }^{5}, v^{2}=2 g h(v=$ velocity, $g=$ acceleration due to gravity and $h=$ height of run-up), which does not take into account frictional losses during movement, a velocity of $112 \mathrm{~m} \mathrm{~s}^{-1}$ is calculated for the debris at the base of the wall. An expression derived by Francis and Baker ${ }^{6}$, which does take into account frictional losses, yields a velocity of $213 \mathrm{~m} \mathrm{~s}^{-1}$.

The magnitude of the run-up at Avalanche Lake is not only the highest

\section{年}
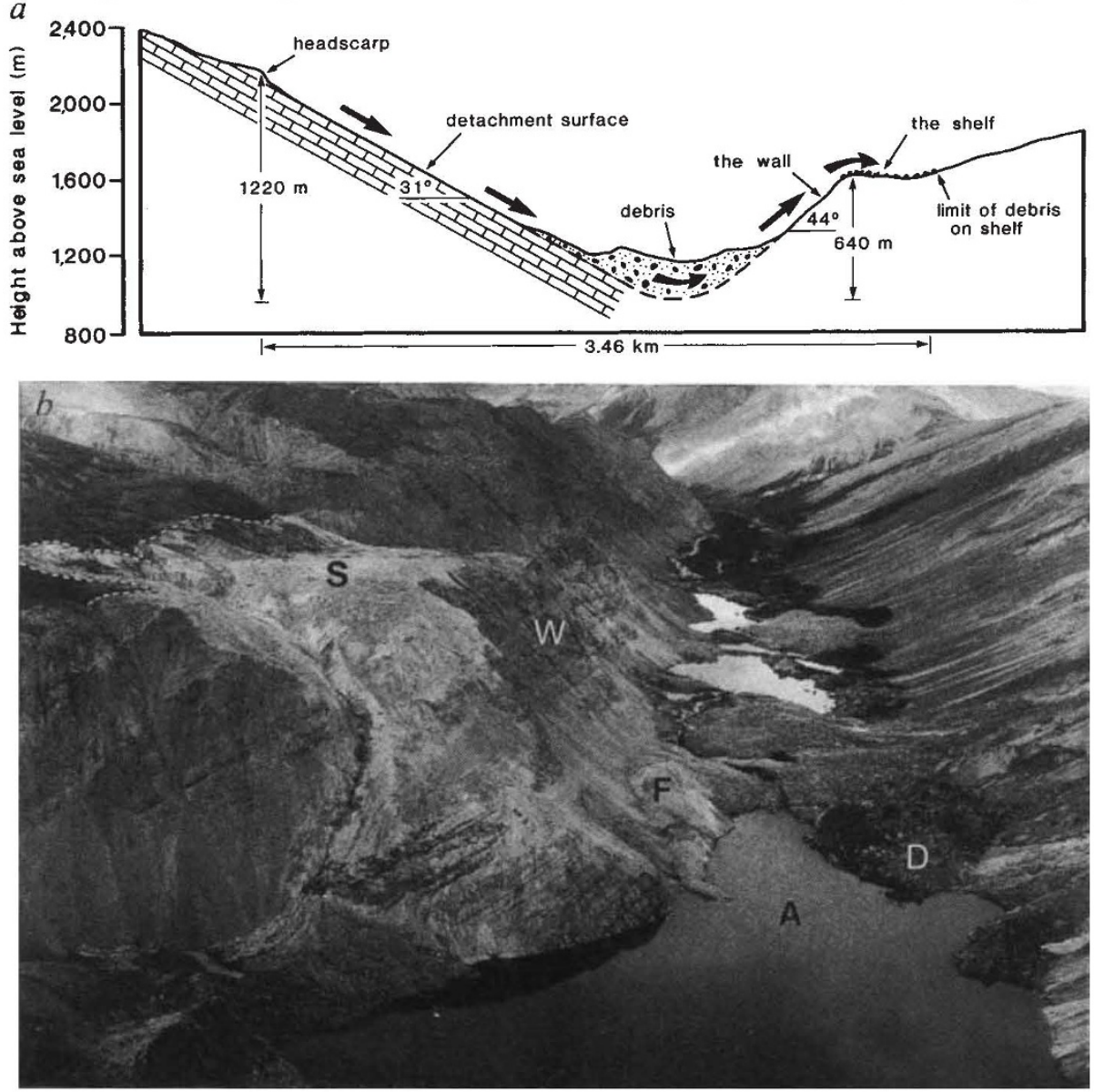

a, Profile of the path of the Avalanche Lake rock avalanche based on 1:50,000 topographic map $95 \mathrm{~L} / 6$. The pre-landslide topography of Avalanche Lake valley was estimated by projecting the thalweg of the unnamed river that occupies the valley beneath the debris. $b$, Oblique aerial view (to the west) downstream of Avalanche Lake (A), showing debris in the valley (D), the shelf (S), the wall $(W)$ and a fallback ridge $(F)$ at the wall's base. Debris can be seen on the shelf and secondary run-up, the upper limit of which is delineated by the dashed line, at the shelf's southern margin. recorded but is also highly anomalous in relation to $h_{1}$. A plot of $h_{1}$ against $h_{2}$ for 24 rock avalanches from around the world (unpublished data) shows that a line equivalent to $h_{2}=0.3 h_{\mathrm{i}}$ clearly defines an upper limit for the data. But for the Avalanche Lake data $h_{2}=0.52 h_{1}$.

During field work at Avalanche Lake in 1987, numerous wood fragments were found scattered throughout the debris of the shelf lobe. Typically, the fragments consisted of broken logs and splinters and were wedged beneath or between boulders in the debris. Splinters were also found at the strand line of the secondary run-up at the southern margin of the shelf. The shelf is above the tree line and no tree fragments were found beyond the limits of the shelf lobe debris. The nature and the distribution of the wood fragments clearly suggests that they were incorporated into the debris as the avalanche smashed through trees during its travel over the valley floor of the main Avalanche Lake valley, which is below the current tree-line and which sustains scattered tree-growth beyond the debris (part $b$ of figure).

Radiocarbon dating (by the Radiocarbon Laboratory of the Geological Survey of Canada) of four fragments of wood, one of which was collected by P.K. Kaiser and J.V. Simmons, yields a youngest date of $320 \pm 50 \mathrm{yr}$ before present. Using the calibration curves of Stuiver and Pearson ${ }^{7}$, this date indicates that the avalanche occurred no earlier than 1450 AD.

Geological Survey of Canada, STEPHEN G. EVANS

601 Booth Street,

Ottawa, Ontario,

\section{Canada K1A OE8}

1. Harrison, J.V. \& Faicon, N.L.J. Geol. 46, 296-309 (1938). 2. Evans, S.G. et al. Can. geotech. J. (in the press).

3. Gabrielse, H. et al. Geol. Sun. Can. Memoir 366, 153 (1973)

4. Eisbacher, G.H. Can. Geotech, J. 16, 309-334 (1979).

5. Chow, V.T. Open Channel Hydraulics (McGraw-Hill, New York, 1959).

6. Francis, P.W. \& Baker, M.C.W. Nature 270, 164-165 (1977).

. Stuiver, M. \& Pearson, G.W. Radiocarbon 28, 805-838 (1986).

\section{Calcium oscillations}

SIR-Wakui et al. ${ }^{1}$ report that InsPS 3 , a non-metabolized analogue of 1,4,5-inositol trisphosphate $\left(\mathrm{InsP}_{3}\right)$ can induce pulsatile intracellular release, deduced from a measured pulsatile increase in $\mathrm{Ca}^{2+}$ dependent chloride conductance. The InsPS $_{3}$ was introduced into mouse pancreatic acinar cells via a 'whole-cell' patch pipette and presumably achieved a steady intracellular level over the many minutes of the experiments. The authors conclude that intracellular $\mathrm{Ca}^{2+}$ oscillations (at least in mouse pancreatic cells) are not generated by "spiking levels of InsP $\mathrm{P}_{3}$ " and state in their title that "pulsatile intracellular release does not depend on fluctuations in 